\title{
Phase relations in resonant circuits with a wide falling section on the amplitude characteristic
}

\author{
Usmanov E. ${ }^{1}$, Khusanov B. $M^{1}$ \\ ${ }^{1}$ Tashkent State Technical University, Tashkent, 100095, Uzbekistan
}

\begin{abstract}
This article examines the features of circuits in order to determine the possibility of their use for controlling thyristors when building new, simple and reliable circuits for controlling boost voltage stabilizers. In ferroresonant circuits connected to a voltage source with a low internal resistance, with a certain combination of parameters, oscillations are excited at the fundamental frequency, the initial phase of which has a shift with respect to the phase of the applied voltage. Moreover, the phase of the excited oscillations depends on the magnitude of the applied emf.
\end{abstract}

Key words: linear inductance, parallel circuit, capacitor, conductivity, nonlinear circuit, magnetic flux.

\section{Introduction}

The studies carried out when creating a thyristor control device as a function of the input voltage have shown that ferroresonant circuits with a falling section on the amplitude characteristic can be used as a sensitive organ of this device.

\section{Main part}

Consider the phase relationships of a parallel resonant circuit connected in series with a linear inductance. Simple graphical constructions of the I - V characteristic of a three-element circuit according to the characteristics of individual links clearly shows that the amplitude characteristic of the circuit has a wide area of the falling section. To reveal the phase relationships, we will carry out a theoretical analysis of the circuit under consideration, the equivalent circuit of which is shown in Fig. 1 [1-5].

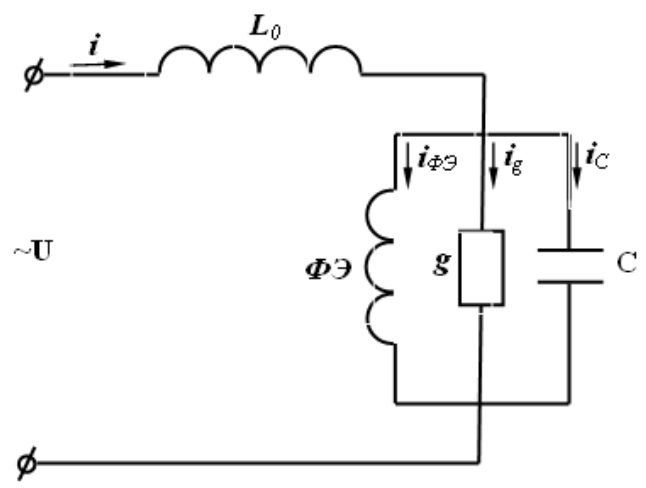

Figure: 1. Equivalent circuit of a parallel auto-parametric circuit with a linear inductive resistance connected in series to it.
To carry out a theoretical analysis, we make the following assumptions:

Hysteresis losses, eddy currents and active resistance of the nonlinear PV winding are considered constant and are taken into account by the conductivity $g$ connected in parallel with the PV [6-8].

We neglect the losses in the capacitance $\mathrm{C}$ and the leakage inductance of the PV windings.

Only the fundamental harmonic of the harmonically varying magnetic flux is taken into account.

The PM flux curve belongs to the category of symmetric characteristics, so it should be approximated by an odd power function.

In addition, we neglect the losses in the core of the linear choke, in view of their smallness [10-14].

The research is carried out by the method of slowly varying amplitudes. The investigated circuit is described by the following differential equation:

$$
\mathrm{u}=\mathrm{w} \frac{\mathrm{d} \phi}{\mathrm{dt}}+\mathrm{L}_{0} \frac{\mathrm{di}}{\mathrm{dt}}
$$

where

$$
\mathrm{i}=\mathrm{i}_{\mathrm{C}}+\mathrm{i}_{\mathrm{g}}+\mathrm{i}_{\Phi \ni}
$$

Here

$$
\begin{gathered}
\mathrm{i}_{C}=w C \frac{\mathrm{d}^{2} \phi}{\mathrm{dt}^{2}} \\
\mathrm{i}_{\mathrm{g}}=\mathrm{wg} \frac{\mathrm{d} \phi}{\mathrm{dt}} ; \\
\mathrm{i}_{\Phi \ni}=\frac{\mathrm{K}}{\mathrm{w}} \phi^{7}
\end{gathered}
$$

Taking into account expressions (3-5), we rewrite the equation (1) 


$$
\begin{gathered}
u=w \frac{d \phi}{d t}+w C L_{0} \frac{d^{2} \phi}{d t^{2}}+w g L_{0} \frac{d^{2} \phi}{d t}+\frac{K L_{0}}{w} \frac{d \phi^{7}}{d t} \\
y=\frac{u}{U_{\sigma}} ; \quad x=\frac{\phi}{\Phi_{\sigma}} ; \quad \Phi_{\sigma}=\sqrt[6]{\frac{64 \omega^{2} w^{2} C}{35 K}} ; \\
\mathrm{U}_{\sigma}=\omega \mathrm{w} \Phi_{\sigma} ; \quad \tau=\omega \mathrm{t} .
\end{gathered}
$$

Here, the amplitude value of the first harmonic of the magnetic flux, determined from the condition of equality of the amplitude values of the currents in the PV winding and capacitor $\mathrm{C}$, connected in parallel, is taken as the basic value of the magnetic flux, which corresponds to the point of intersection of wax of the PV and capacitor $\mathrm{C}$ [15-18].

Therefore, it is determined from the equality condition

$$
\frac{35 \mathrm{~K}}{64 \mathrm{w}} \Phi_{\mathrm{m}}^{7} \operatorname{Sin}(\tau+\psi)=\omega^{2}{ }_{\mathrm{wC}} \Phi_{\mathrm{m}} \operatorname{Sin}(\tau+\psi)
$$

taking into account expressions (7), after simple transformations, equation (6) will have the following form:

$$
\begin{aligned}
y & =\frac{d x}{d \tau}+\omega^{2} C L_{0} \frac{d^{3} x}{d \tau^{3}}+\omega g L_{0} \frac{d^{2} x}{d \tau^{2}}+ \\
+\omega^{2} C L_{0} \frac{64}{35} \frac{d x^{7}}{d \tau} &
\end{aligned}
$$

taking dimensionless coefficients

$$
\beta=\omega^{2} C L_{O} ; \quad \gamma=\omega L_{O} g
$$

we have

$$
y=\frac{d x}{d \tau}+\beta \frac{d^{3} x}{d \tau^{3}}+\gamma \frac{d^{2} x}{d \tau^{2}}+\beta \frac{64}{35} \frac{d \phi^{7}}{d \tau}
$$

Let us integrate this equation

$$
\int y d x+c=x+\beta \frac{d^{2} x}{d \tau^{2}}+\gamma \frac{d x}{d \tau}+\frac{64}{35} \frac{d \phi^{7}}{d \tau} \beta x^{7}
$$

where $\mathrm{c}$ is the constant of integration.

We will seek solution (11) in the form

$$
x=X_{m} \operatorname{Sin}(\tau+\psi) \text { at. } y=y_{m} \operatorname{Sin} \tau
$$

Derivative of $\mathrm{x}$; looks like:

$$
\begin{array}{r}
\frac{d x}{d \tau}=\frac{d X_{m}}{d \tau} \operatorname{Sin}(\tau+\psi)+X_{m} \operatorname{Cos}(\tau+\psi)+ \\
+\frac{d \psi}{d \tau} X_{m} \operatorname{Cos}(\tau+\psi)
\end{array}
$$

Taking into account that $X_{m} \gg \frac{d X_{m}}{d \tau}$ and $X_{m} \gg \frac{d \psi}{d \tau} X_{m}$ can be taken as a first approximation

$$
\begin{gathered}
\frac{d x}{d \tau}=X_{m} \operatorname{Cos}(\tau+\psi) \\
\frac{d^{2} x}{d \tau^{2}}=\frac{d^{2} X_{m}}{d \tau^{2}} \operatorname{Sin}(\tau+\psi)+\frac{d X_{m}}{d \tau} \operatorname{Cos}(\tau+\psi)+ \\
+\frac{d X_{m}}{d \tau} \frac{d \psi}{d \tau} X_{m} \operatorname{Cos}(\tau+\psi)+\frac{d X_{m}}{d \tau} \operatorname{Cos}(\tau+\psi) \\
+\frac{d X_{m}}{d \tau} \frac{d \psi}{d \tau} \operatorname{Cos}(\tau+\psi)+X_{m} \frac{d^{2} \psi}{d \tau^{2}} \operatorname{Cos}(\tau+\psi) \\
X_{m} \frac{d \psi}{d \tau} \operatorname{Sin}(\tau+\psi) \\
X_{m} \frac{d \psi}{d \tau} \operatorname{Sin}(\tau+\psi)+ \\
X_{m}\left(\frac{d \psi}{d \tau}\right)^{2} \operatorname{Sin}(\tau+\psi)
\end{gathered}
$$

From (14), neglecting the second-order terms and taking into account the first harmonic of the magnetic flux, we have:

$$
\begin{gathered}
\frac{d^{2} x}{d \tau^{2}}=2 \frac{d X_{m}}{d \tau} \operatorname{Cos}(\tau+\psi) 2 X_{m} \frac{d \psi}{d \tau} \operatorname{Sin}(\tau+\psi) \\
X_{m} \operatorname{Sin}(\tau+\psi)
\end{gathered}
$$

Substituting (14) and (4) into equation (11) we obtain

$$
\begin{aligned}
& y_{m} \operatorname{Cos} \tau=-X_{m} \operatorname{Sin}(\tau+\psi)-2 \beta \frac{d X_{m}}{d \tau} \operatorname{Cos}(\tau+\psi)+ \\
& +2 \beta \frac{d \psi}{d \tau} \operatorname{Sin}(\tau+\psi)++\beta X_{m} \operatorname{Sin}(\tau+\psi)- \\
& -\gamma X_{m} \operatorname{Cos}(\tau+\psi)-\beta X_{m}^{7} \operatorname{Sin}(\tau+\psi)
\end{aligned}
$$

After simple trigonometric transformations, we group the coefficients of the same trigonometric functions

$$
\begin{array}{r}
y_{m} \operatorname{Sin} \psi=-X_{m}+2 \beta \beta m \frac{d \psi}{d \tau}+\beta X_{m}-\beta X_{m}^{7} \\
y_{m} \operatorname{Cos} \psi=-\gamma X_{m}-2 \beta \frac{d X_{m}}{d \tau}
\end{array}
$$

For the stationary state

$$
\begin{gathered}
y_{m} \operatorname{Sin} \psi=\beta X_{m}+\beta X_{m}-X_{m}^{7} \\
y_{m} \operatorname{Cos} \psi=-\gamma X_{m}
\end{gathered}
$$

The joint solution of equations (18), (19) gives the amplitude value of the input voltage, in relative units and the phase angle between the voltage of the power supply and the magnetic flux of the PV [19-22].

$$
y_{m}=\sqrt{\left[\beta\left(1-X_{m}^{6}\right]^{2}-\gamma^{2}\right.}
$$




$$
\operatorname{tg} \psi=-\frac{\beta\left(1-X_{m}^{6}\right)-1}{\gamma}
$$

To construct the I-V characteristic of the circuit and determine its amplitude-phase characteristic, it is necessary to determine the dependences $I=f(\Phi)$ and $\Phi=f\left(U_{B x}\right)$

Let us rewrite equation (2) taking into account (3), (4) and (5)

$$
i=w C \frac{d^{2} \phi}{d t^{2}}+w g \frac{d \phi}{d t}+\frac{K}{w} \phi^{7}
$$

introducing new dimensionless and basic quantities

$$
z=\frac{i}{I_{\sigma}} ; \quad I_{\sigma}=2_{w C \Phi}
$$

and taking into account expressions (7), (9), we rewrite equation (21) in the form

$$
z=\frac{d^{2} x}{d \tau^{2}}+\frac{g}{\omega C} \frac{d x}{d \tau}+\frac{64}{35} x^{7}
$$

or

$$
z=\frac{d^{2} x}{d \tau^{2}}+\frac{g}{\delta} \frac{d x}{d \tau}+\frac{64}{35} x^{7}
$$

Suppose

$$
z=Z_{m} \operatorname{Sin}(\tau-\varphi)
$$

Taking into account (11), (12) and (24) into equation (24) and taking into account the fundamental harmonic of the magnetic flux, we have:

$$
\begin{aligned}
& Z_{m} \operatorname{Sin}(\tau-\varphi)=-X_{m} \operatorname{Sin}(\tau+\psi)+\frac{\gamma}{\beta} X_{m} \operatorname{Cos}(\tau+\psi)+ \\
& +X_{m}^{7} \operatorname{Sin}(\tau+\psi)
\end{aligned}
$$

After simple transformations and grouping of coefficients for the same trigonometric functions, we have:

$$
\begin{gathered}
Z_{m} \operatorname{Sin} \varphi=-\left(X_{m}^{6}-1\right) X_{m} \operatorname{Sin} \psi-\frac{\gamma}{\beta} X_{m} \operatorname{Cos} \psi \\
Z_{m} \operatorname{Cos}=\left(X_{m}^{6}-1\right) X_{m} \operatorname{Cos} \psi-\frac{\gamma}{\beta} X_{m} \operatorname{Sin} \psi
\end{gathered}
$$

The joint solution of equations (26) and (27) gives the amplitude value of the load current in relative units and the phase angle between the load current and the supply voltage:

$$
Z_{m}=X_{m} \sqrt{\left(1-X_{m}^{6}\right)^{2}-\left(\frac{\gamma}{\beta}\right)^{2}}
$$

$$
\operatorname{tg} \varphi=-\frac{\left(X_{m}^{6}-1\right) \operatorname{tg} \psi-\frac{\gamma}{\beta}}{\left(X_{m}^{6}-1\right)-\frac{\gamma}{\beta} \operatorname{tg} \psi}
$$

The results obtained by formula (29) have both positive and negative values:

- the negative value of the angle $\varphi$ corresponds to the phase advance of the load current, from the mains voltage;

- a positive value of the angle $\varphi$ corresponds to the lag of the load current phase from the power supply voltage.

\section{Conclusions}

1. Revealed the peak value of the load current in relative units and the phase angle between the load current and the supply voltage.

2. The analysis of the phase relationships of the resonant circuit connected in series with the inductance showed that the initial phase of the current in the unbranched part of the circuit changes inversely with the value of the applied voltage and has a wide range of dependence on changes in the input voltage.

3. Possibilities of obtaining amplitude - phase relations of a given form when using a circuit to control the states of thyristors as a function of voltage have been established.

\section{References}

1. E.G. Usmanov, A.N. Rasulov, M.K. Bobojanov, R.Ch. Karimov. Non-contact voltage relay for switching windings of a boost transformer // E3S Web of Conferences $\quad 139, \quad 01079 \quad$ (2019), doi.org/10.1051/e3sconf/201913901079

2. R.Ch.Karimov, MK Bobojanov, AN Rasulov, EG Usmanov. Controlled switching circuits based on nonlinear resistive elements // E3S Web of Conferences $139, \quad 01039$

(2019),

doi.org/10.1051/e3sconf/201913901039

3. Bobojanov M.K., Usmanov E.G., Abduraimov E.H., Karimov R.Ch. Resistive time delay switches // Scientific journal «European Science Review» (ISSN: 2310-5577). Vienna (Austria), January-February. - №12. - PP.210-212 (2018).

4. Rakhmonov,I., Berdishev,A., Khusanov,B.M, Khal iknazarov, U., Utegenov, U. General characteristics of networks and features of electricity consumers in rural areas//IOP Conference Series: Materials Science and Engineering, 2020, 883(1), 012104.

5. Khakimov, H.T., Shayumova, Z.M., Kurbanbaeva, Z.K., Khusanov, B.M. Development of optimal modes and mathematical models of energy performance of electric steelmaking production//E3S Web of Conferences, 2019, 139, 01076

6. Saidkhodjaev A G, Najimova A M and Bijanov A K 2019 Method for determining the maximum load of 
consumers in city power supply systems E3S Web Conf 139 doi:10.1051/e3sconf/201913901078.

7. Taslimov A D, Rakhmonov I U 2019 Optimization of complex parameters of urban distribution electric networks Journal of Physics: Conference Series 1399 doi:10.1088/1742-6596/1399/5/055046

8. Rakhmonov I U, Niyozov N N 2019 Optimization setting of steel-smelting industry in the issue of alloy steels E3S Web Conf 139 doi:10.1051/e3sconf/201913901077

9. Mannanov U., Toshov J., Toshniyozov L. Perspective Solutions for the Design of Drilling Tools / E3S Web of Conferences 105, 03027 (2019) IVth International Innovative Mining Symposium, https://doi.org/10.1051/e3sconf/201910503027

10. Azamatovich, A.N., Amrillo, M.B, Burievich, T.J., Umarxanoxich, J.R., Shavkatovich, Z.A. A complex of methods for analyzing the working fluid of a hydrostatic power plant for hydraulic mining machines / International Journal of Advanced Science and Technology. Volume 29, Issue 5 Special Issue, 28 March 2020, Pages 852-855

11. Rakhmonov I U, Reymov K M and Shayumova Z M 2019 The role information in power management tasks. E3S Web Conf 139 doi:10.1051/e3sconf/201913901080 12. Hoshimov, F.A., Bakhadirov, I.I., Erejepov, M., Djumamuratov, B. (2019) Development of method for normalizing electricity consumption E3S Web Conf 139 doi:10.1051/e3sconf/201913901074

13. Rakhmonov I U, Tovbaev A N, Nematov L A and Alibekova T Sh 2020 Development of forecasted values of specific norms for the issues of produced products in industrial enterprises Journal of Physics: Conference Series 1515 doi:10.1088/1742-6596/1515/2/022050

14. Rakhmonov I U, Nematov L A, Niyozov N N, Reymov K M and Yuldoshev T M 2020 Power consumption management from the positions of the general system theory Journal of Physics: Conference Series 1515 doi:10.1088/1742-6596/1515/2/022054

15. Rakhmonov I U, Reymov K M, Najimova A M, Uzakov B T and Seytmuratov BT 2019 Analysis and calculation of optimum parameters of electric arc furnace Journal of Physics: Conference Series 1399 doi:10.1088/1742-6596/1399/5/055048

16. Taslimov A D, Berdishev A S, Melikuzuev M V and Rakhimov F M 2019 Method of selecting parameters of cable lines distributive networks $10 \mathrm{kv}$ in uncertainty $\begin{array}{lllll}\text { conditions } & \text { E3S } & \text { Web } & \text { Conf } & 139\end{array}$ doi:10.1051/e3sconf/201913901082

17. Taslimov A D, Berdishev A S, Melikuziyev M V and Rakhimov F M 2019 Method of choosing the unification of cable sections of electric network cables under conditions of load development uncertainty E3S Web Conf 139 doi:10.1051/e3sconf/201913901081

18. Karimov R.Ch., Shamsiyev K., and others. IOP Conf. Series: Materials Science and Engineering, 883(1), 012142, (2020). doi:10.1088/1757$899 X / 883 / 1 / 012142$

19. Karimov R.Ch., Shamsiyeva N. and others. IOP Conf. Series: Materials Science and Engineering, 883(1), 012120, (2020). doi:10.1088/1757$899 X / 883 / 1 / 012120$
20. Burievich, T.J. The questions of the dynamics of drilling bit on the surface of well bottom// Arch. Min. Sci. -Poland. - Vol. 61 (2016). - №2. - P. 279-287. DOI 10.1515/amsc-2016-0020.

21. Toshniyozov, L.G., Toshov, J.B. Theoretical and experimental research into process of packing in drilling// Mining Informational and Analytical Bulletin Volume 2019, Issue 11, 2019, Pages 139-151. DOI: 10.25018/0236-1493-2019-11-0-139-151.

22. G.R.Rafikova, M.R.Ruzinazarov, S.K.Makhmutkhonov. E3S Web of Conferences, 139, 01075 ,

https://doi.org/10.1051/e3sconf/201913901075
(2019), 